\title{
Void growth in 6061-aluminum alloy under triaxial stress state
}

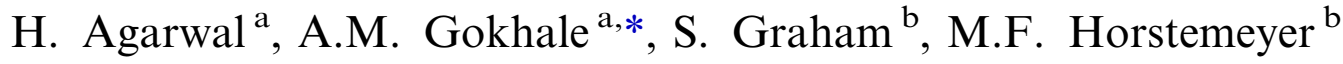 \\ ${ }^{a}$ School of Materials Science and Engineering, Georgia Institute of Technology, Atlanta, GA 30332-0245, USA \\ ${ }^{\mathrm{b}}$ Sandia National Laboratories, Livermore, CA, USA
}

Received 6 June 2001; received in revised form 2 October 2001

\begin{abstract}
In numerous metals and alloys, ductile fracture involves void nucleation, growth, and coalescence. In this contribution, void growth has been quantitatively characterized in an extruded 6061-wrought Al-alloy as a function of stress state in notch tensile test specimens. Digital image analysis and Stereology have been used to estimate the volume fraction and three-dimensional number density of voids in a series of interrupted notch tensile test specimens where the local stress state is predominantly triaxial. Finite elements (FE) simulations have been used to compute the stress states at different locations in the specimens. The computed stress states and experimentally estimated average void volume are utilized to verify analytical void growth models. Lack of agreement between the predictions of the models and the experimental data is due to interactions between neighboring voids, which are ignored in the theoretical models, and continuous void nucleation. The following empirical damage evolution equation is obtained from the experimental data on void volume fraction expressed as $\%(f)$, and the corresponding local equivalent plastic strain $\left(\varepsilon_{\mathrm{p}}\right)$ and stress triaxiality $(I)$ computed from FE simulations: $f=a+b \ln \left[\varepsilon_{\mathrm{p}}\right]+c I$. In this equation, $a, b$ and $c$ are empirical constants whose values depend on the alloy chemistry, heat treatment, and microstructure. The equation is useful only for 6061(T6) Al-alloy.
\end{abstract}

(C) 2002 Elsevier Science B.V. All rights reserved.

Keywords: Void growth; Damage; Aluminum alloys; Image analysis; Quantitative metallography

\section{Introduction}

6XXX series of wrought aluminum alloys are widely used for automotive and aerospace structural applications due to their good extrudability, weldability, and excellent corrosion resistance. Aluminum 6061 is a typical alloy of this series that is used for applications such as canoes, railroad cars, towers, pipelines, and other medium strength structures where good weldability and excellent corrosion resistance are needed. Microstructure of 6061 Al-alloy contains inclusions/ particles of brittle phases dispersed in a ductile matrix (Fig. 1). Ductile fracture of such alloys involves cracking of brittle phase inclusions/particles (damage initiation/ nucleation), growth of voids around the cracked brittle phase particles/inclusions, and void coalescence. It is observed that significant void growth occurs only under

\footnotetext{
* Corresponding author. Tel.: +1-404-894-2887; fax: +1-404-8949140

E-mail address: arun.gokhale@mse.gatech.edu (A.M. Gokhale).
}

a triaxial stress state [1]. Therefore, to understand such damage evolution process, it is of interest to quantitatively characterize void growth under a loading condition that generates significant triaxiality in the stress state. Accordingly, in this contribution, void growth around cracked iron rich intermetallic particles is quantitatively characterized in a series of notch-tension test specimens of a peak aged extruded 6061 Al-alloy, as a function of equivalent plastic strain and stress triaxiality. The experimental data have been utilized to verify void growth models, and to generate an empirical damage evolution relationship for this alloy. A brief background on the void growth models is given in Section 2. The experimental work and results are presented in the subsequent sections.

\section{Void growth models}

Numerous analytical void growth rules have been developed under different assumptions [2-6]. Rice and Tracey [6] have developed a void growth model, which 


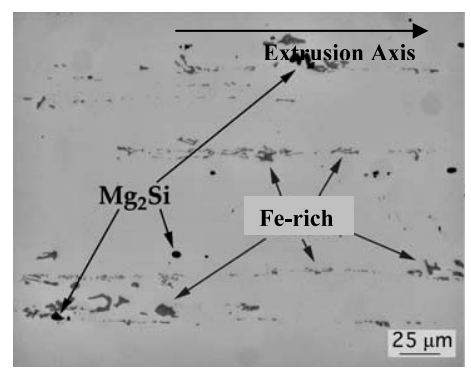

Fig. 1. Typical microstructure of the 6061 Al-alloy in an unetched condition.

predicts the growth of a void in an infinite, rigid, perfectly plastic material subjected to a uniform remote strain field. Their model assumes that there is only one spherical void, which is embedded in a rigid perfectly plastic matrix of infinite size. According to Rice and Tracey [6], the void growth can be described by the following equation:

$\left[\frac{\mathrm{d} R}{R}\right]=\alpha \exp \left(\frac{3 \sigma_{\mathrm{m}}}{2 \sigma_{\mathrm{eq}}}\right) \mathrm{d} \varepsilon_{\mathrm{eq}}^{\mathrm{p}}$

In Eq. (1), $R$ is the radius of the void; $\sigma_{\mathrm{m}}$, hydrostatic stress, equal to $\sigma_{i i} / 3 ; \varepsilon_{\mathrm{eq}}^{\mathrm{p}}$, equivalent plastic strain; $\sigma_{\mathrm{eq}}$, Von Mises equivalent stress; and $\alpha$, constant. A value $\alpha=0.283$ was proposed by Rice and Tracey. Eq. (1) can be integrated and represented in the following form:

$\ln \left[\frac{V}{V_{0}}\right]=3 \alpha \int_{\varepsilon_{0}}^{\varepsilon} \exp \left(\frac{3 \sigma_{\mathrm{m}}}{2 \sigma_{\mathrm{eq}}}\right) \mathrm{d} \varepsilon_{\mathrm{eq}}^{\mathrm{p}}$

In Eq. (2), $V$ is the void volume at the equivalent plastic strain $\varepsilon$, and $V_{0}$ is the initial void volume at the equivalent plastic strain $\varepsilon_{0}$.

McClintock [2] has proposed a model for the void growth, which predicts the growth of an elliptical hole in a viscous material under an applied stress, using an axisymmetric geometry. However, McClintock's model is considered to be a good approximation for growth of spherical voids as well, and recently it has been successfully applied to model damage evolution involving nucleation, growth, and coalescence of voids in three-dimensional microstructure of a cast A356 alloy $[7,8]$. For growth of a spherical void, the model gives the following equation:

$$
\begin{aligned}
V_{\text {void }}= & \frac{4}{3} \pi\left(R_{0} \exp [\varepsilon(t)\right. \\
& \left.\left.\times \frac{\sqrt{3}}{2(1-n)} \sin h\left(\sqrt{3}(1-n) \frac{\sqrt{2} I_{1}}{3 \sqrt{J_{2}}}\right)\right]\right)^{3}
\end{aligned}
$$

In Eq. (3), $R_{0}$ is the initial radius of a spherical void and $V_{\text {void }}$ is its volume after pore growth at equivalent strain level of $\varepsilon(t), n$ is the strain-hardening exponent, $I_{1}$ is the first invariant of the stress tensor $\left(I_{1}=\sigma_{k k}\right)$, and $J_{2}$ is the second invariant of the stress tensor $\left(J_{2}=(1 / 2) S_{i j} S_{i j}\right.$ and $\left.S_{i j}=\sigma_{i j}-(1 / 3) \delta_{i j} \sigma_{k k}\right)$. This equation reveals that stress triaxiality, strain-hardening coefficient, strain rates, temperature regimes, etc. have dominant influence on the void growth rate.

\section{Experimental}

The experiments were performed on the specimens drawn from $88 \mathrm{~mm}$ diameter extruded round bar of 6061 Al-alloy in T651 condition, supplied by ALCOA. The chemical composition of the alloy is given in Table 1. In the extruded alloy, the $\mathrm{Mg}_{2} \mathrm{Si}$ and Fe-rich intermetallic constituent particles are aligned along the extrusion axis (Fig. 1).

\subsection{Notch-tension tests}

In the extruded Al-alloy bar stock, microstructural/ chemical gradients may exist in the radial direction. To ensure that all test specimens have statistically similar microstructure and the same alloy chemistry, all the specimens were extracted from the bar stock at a radial distance of $20 \mathrm{~mm}$ from the bar center. For the notch tension tests, the loading direction was parallel to the extrusion axis. These tests were performed on a MTS 880 servo-hydraulic test frame. Specimens having two different notch radii were used in order to vary the induced levels of stress triaxiality. Notched-tension test samples contained a gage section, which was $12.7 \mathrm{~mm}$ in diameter and they contained notch of either 19.8 or 2.49 $\mathrm{mm}$ radius. The geometry of the notched tensile test specimens is shown in Fig. 2. To study void growth as a function of triaxial stress-state, a series of interrupted tests were performed at different displacements ranging from 75 to $98 \%$ of the failure displacement. The specimen displacements were monitored by using an extensometer that spanned the entire notched region. Figs. 3

Table 1

Chemical composition of 6061 Al-alloy

\begin{tabular}{lllllllllll}
\hline Element & $\mathrm{Zn}$ & $\mathrm{Ti}$ & $\mathrm{Si}$ & $\mathrm{Mn}$ & $\mathrm{Mg}$ & $\mathrm{Fe}$ & $\mathrm{Cu}$ & $\mathrm{Cr}$ & $\mathrm{Al}$ \\
\hline Wt.\% & 0.02 & 0.01 & 0.65 & 0.04 & 1.06 & 0.37 & 0.28 & 0.2 & Balance \\
\hline
\end{tabular}




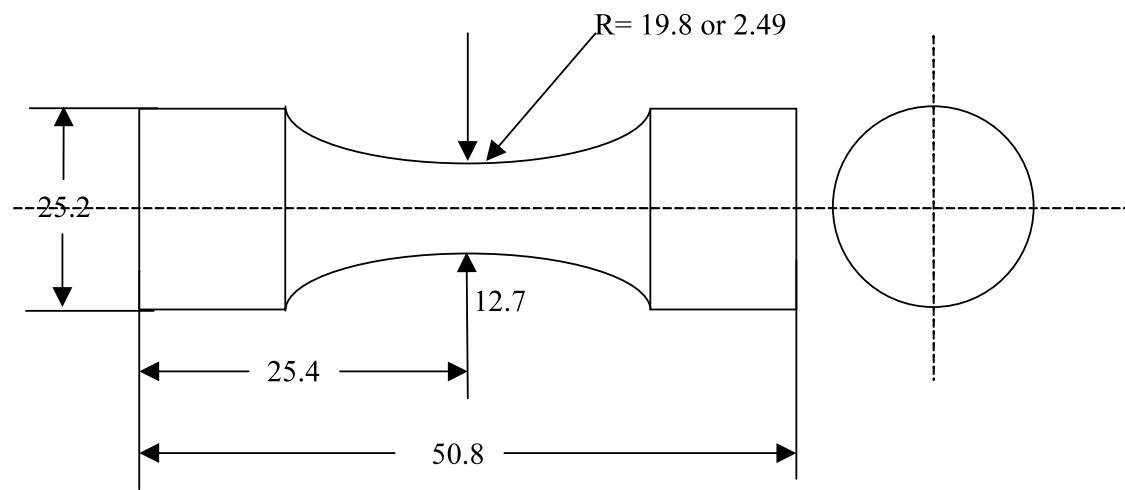

All dimensions in $\mathrm{mm}$

Fig. 2. Geometry of notch-tension test specimens.

and 4 show load displacement curves of two different notch radii specimens.

\subsection{Finite element simulations}

In the notched tension test specimens, the parameters such as stress triaxiality and equivalent plastic strain vary significantly in the notch region. Further, these parameters can also be varied in a controlled manner by changing the notch radius, which provides an opportunity to study the effect of stress triaxiality and other

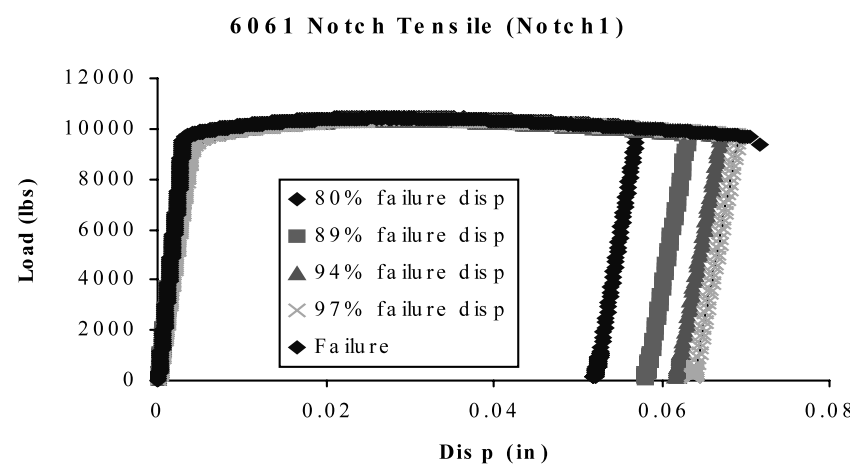

Fig. 3. Load-displacement curve for the notch-tension test specimen having $19.8 \mathrm{~mm}$ notch radius.

\section{Notch-Tensile (Notch3)}

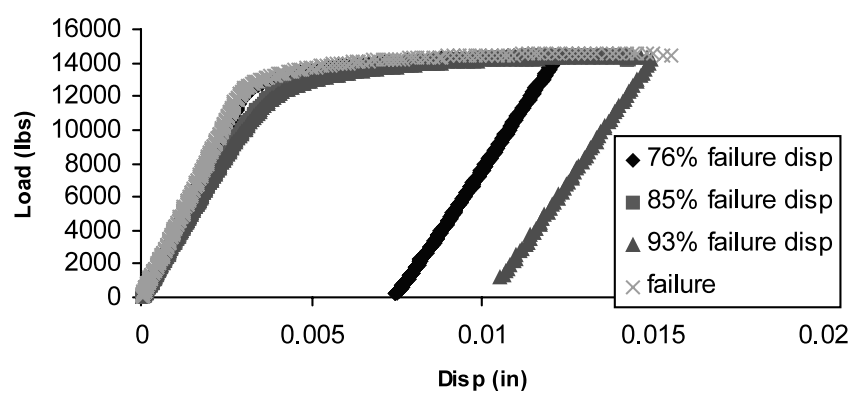

Fig. 4. Load-displacement curve for the notch-tension test specimen having $2.49 \mathrm{~mm}$ notch radius. parameters of stress state on void growth. The geometry of the present notch-tension specimens is such that, in a given specimen at a given applied load/displacement, the stress triaxiality is the highest at the center of the specimen in the notch region, and the lowest at the edge, whereas the plastic strain is the lowest at the center and the highest at the edge. To understand the dependence of void growth on the stress state, FE-based simulations were performed to compute the maximum principal stress, stress triaxiality, and equivalent plastic strain in the notch region of the specimens for different applied load/displacement levels using ABAQUS software package. The FE-simulations are based on the following:

1) Experimental uniaxial tension stress-strain curve of 6061 alloy [11] was used as the constitutive equation in the FE-model to simulate the elastic-plastic response. The simulations were performed using the PLASTIC computer code of the ABAQUS package.

2) The simulations were performed on the specimens whose geometry is shown in Fig. 2. The preprocessing was carried out using I-DEAs software package.

3) The CAX4 elements were used for simulations.

4) The simulation involved 300 elements for specimen having notch radius of $19.8 \mathrm{~mm}$, and 380 elements for the specimen having $2.49 \mathrm{~mm}$ notch radius.

5) Displacement controlled simulations were performed to compute the local stress state parameters such as stress triaxiality, equivalent plastic strain, Von Mises stress, maximum principal stress, etc. as a function of location and displacement.

\subsection{Metallography}

The specimens were cut in the center along vertical planes containing the applied load direction. The specimens were mounted and then polished on the 180-grit paper. All the polishing was done on wet polishing 
papers to avoid particles from the polishing paper from getting embedded in the soft aluminum matrix; excess pressures were avoided for the same reason. The polishing on papers was continued till 1200 grit size. After this, the lapping cloths were used. The diamond suspension was used as the abrasive medium. This was continued till $1-\mu \mathrm{m}$ suspension, and then the specimens were polished on $0.3-\mu \mathrm{m}$ alumina suspensions. Finally, the polishing was carried out with $0.06-\mu \mathrm{m}$ colloidal silica suspensions to get the required metallographic finish [1]. The specimens were observed under optical microscope in an unetched condition. Fig. 1 shows the typical unetched microstructure of the alloy. Observe that the microstructure contains two types of particles in the aluminum matrix. The light gray particles are $\mathrm{Fe}$ based intermetallics, whereas the black particles are $\mathrm{Mg}_{2} \mathrm{Si}$ intermetallics. In the present work, it has been qualitatively observed that damage due to cracking and void growth around $\mathrm{Mg}_{2} \mathrm{Si}$ intermetallics is negligible in comparison to that due to Fe-rich intermetallics. Therefore, only the void growth around Fe-rich intermetallics has been quantitatively characterized.

\subsection{Quantitative metallography and digital image analysis}

Fig. 6 shows damaged/cracked Fe-rich intermetallic particles as well as growth of micro-voids around these intermetallic particles. In the present microstructures, the voids do not grow around all cracked Fe-rich particles. Therefore, to characterize the active voids, the particle cracks having thickness larger than $1 \mu \mathrm{m}$ are called voids, and only these features are quantitatively characterized. The quantitative microstructural measurements were performed using the KS400 image analyzer with an automatic stage. To avoid the edge effects in the microstructural fields of view, the contiguous fields were grabbed using a CCD camera attached to an optical microscope. The fields were then pasted next to each other in the computer memory to create a seamless montage of images $[9,10]$. In the present work, all the measurements were performed in the notch region of a representative vertical metallographic plane containing the applied load direction. Fig. 5 shows the exact locations, where the measurements were performed in these specimens. At each of the three locations shown in Fig. 5, the void volume fraction and size distribution were measured on a high magnification $(500 \times)$ contiguous digital image montage covering 1.08 $\mathrm{mm}^{2}$ area on the metallographic plane, which covers two elements of the FE-mesh described earlier. The local equivalent plastic strain, stress triaxiality, maximum principal stress, von mises stress, etc. were computed at these exact locations via FE-simulations described earlier. Volume fraction of voids was estimated by using standard stereological techniques [11,12]. The three-

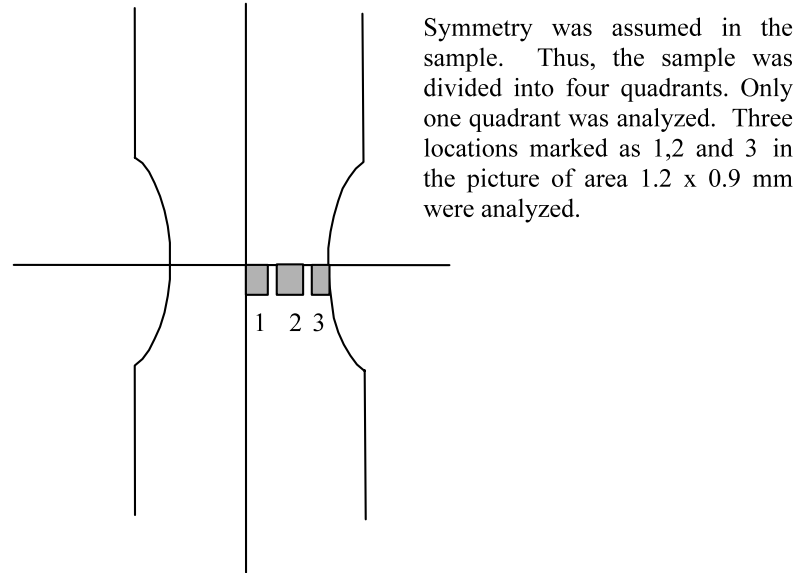

Fig. 5. The exact locations in the notch tension test specimens where the quantitative microstructural measurements have been performed

dimensional number density, size distribution and average volumes of voids were estimated by Saltykov's technique $[11,12]$. In this technique, the void section sizes are converted into true three-dimensional void sizes based on void diameters. The technique involves the complex numerical solution of Abel's integral equation, which relates the two-dimensional section sizes to true three-dimensional sizes based on an assumption that the voids have a spherical shape $[11,12]$. The three-dimensional number density of voids was calculated from the size distribution data.

\section{Results and discussion}

In the notched tension specimens, the deformation is localized in a very narrow zone, where the stress state is predominantly triaxial. Fig. 6 shows damaged/cracked Fe-rich intermetallic particles as well as growth of micro-voids around these intermetallic particles. Note that majority of cracks are perpendicular to notched tensile axis, and the majority of the cracked particles are also parallel to the loading direction. These observations suggest that the damage initiation due to particle cracking is very sensitive to the maximum principal stress. A significant void growth is observed in notched tension specimens (Fig. 6b). The smooth uniaxial tension test specimens [1] did not depict any statistically significant number of damaged particles with voids on them, which illustrates that the stress triaxiality is essential for significant void growth, but it is not essential for particle cracking (i.e. nucleation of voids).

\subsection{Effect of plastic strain and stress triaxiality on void volume fraction}

Figs. 7 and 8 show plots of void volume fraction (\%) versus the local stress triaxiality at the corresponding 

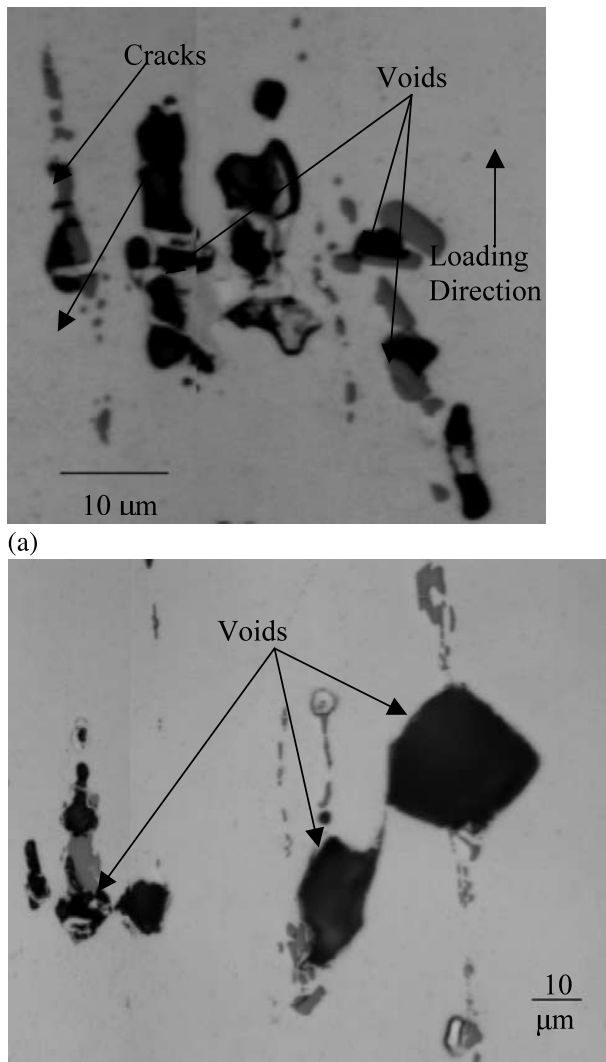

(b)

Fig. 6. (a) Micrograph of a notch tension test specimen showing cracked Fe-rich intermetallics; and (b) void growth around some of the particles.

location, for specimens having notch radius of 19.8 and $2.49 \mathrm{~mm}$, respectively. In these plots, the different data points at each location correspond to the interrupted notch tension test specimens with different applied loads/displacements. Observe that for both the notches: (1) the stress triaxiality decreases significantly from the center (location 1) to the edge (location 3) of the specimen in the notch region (Fig. 5); (2) at a given location, the stress triaxiality does not vary significantly with the applied load (or displacement) for both the notches; and (3) at a given location, the void volume fraction does increase with the applied load/displacement, primarily due to the increase in the equivalent plastic strain with the increase in the applied load/ displacement. Fig. 9 gives a plot of void volume fraction (\%) versus equivalent plastic strain at the corresponding location for specimens having $19.8 \mathrm{~mm}$ radii. Observe that at a given location, the volume fraction increases with the increase in the equivalent plastic strain resulting from an increase in the applied load/displacement. Therefore, the void growth is sensitive to both the stress triaxiality and the equivalent plastic strain.

\subsection{Verification of void growth models}

The average void volume can be computed from the ratio of the experimentally measured void volume fraction and 3D number density of voids computed by Saltykov's technique. Numerous analytical void growth rules have been developed under different assumptions [2-6]. Rice and Tracey [6] have developed a void growth model (see Eq. (1)), which predicts the growth of a spherical void in an infinite, rigid, perfectly plastic material subjected to a uniform remote strain field. Their model assumes that there is only one spherical void, which is embedded in a rigid perfectly plastic matrix. The plastic region of the stress-strain curve of the present 6061 alloy [1] is quite flat and the value of the strain-hardening coefficient is quite low $(n=0.068)$. Therefore, the alloy behavior can be modeled as a perfectly plastic material as assumed by Rice and Tracey. Further, the voids shapes are reasonably

\section{Notch 1}

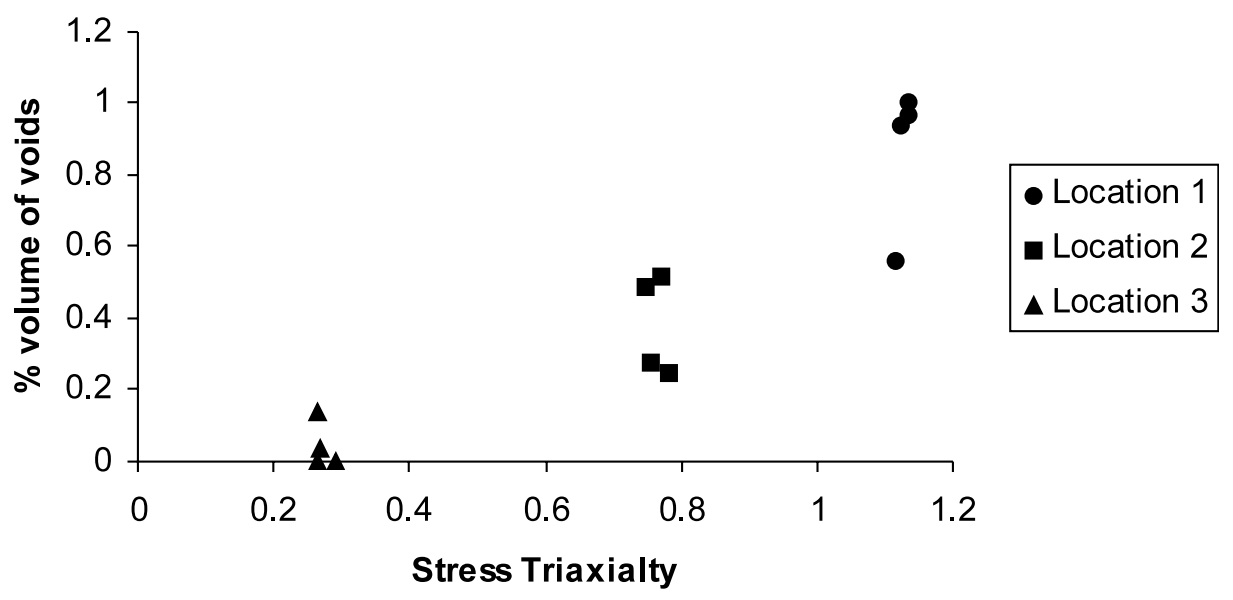

Fig. 7. Plot of void volume fraction (\%) versus stress triaxiality for specimens having $19.8 \mathrm{~mm}$ notch radius. 


\section{Notch 2}

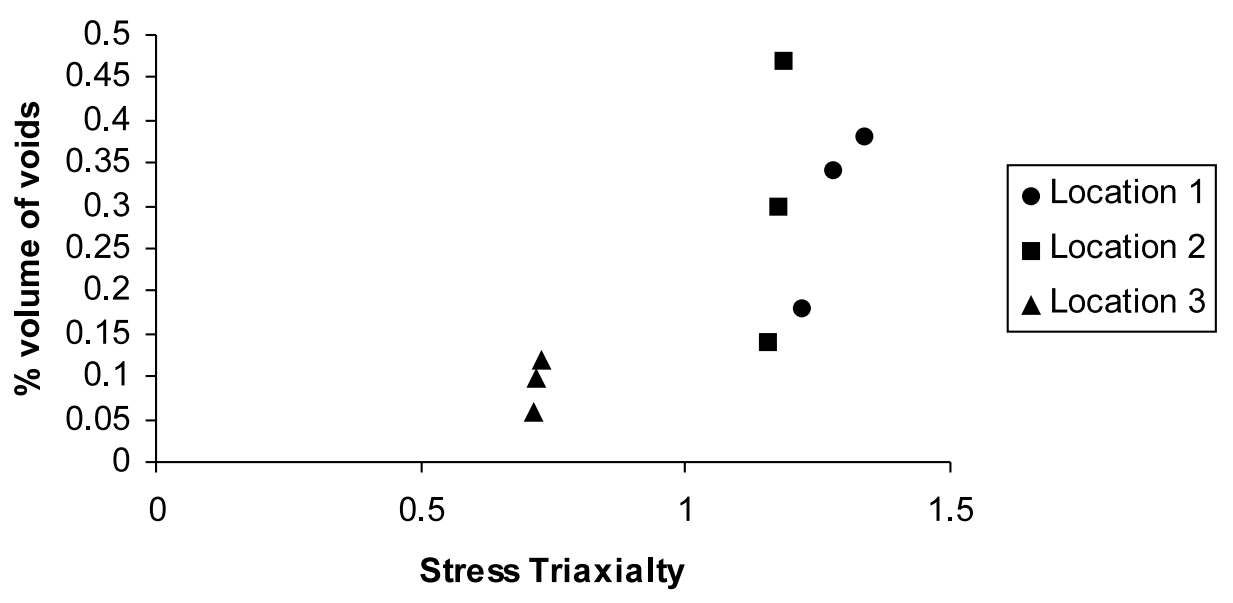

Fig. 8. Plot of void volume fraction (\%) versus stress triaxiality for specimens having $2.49 \mathrm{~mm}$ notch radius.

equiaxed, and therefore, the voids can be assumed to be spherical. Thus, the material satisfies the two important assumptions of Rice and Tracey model, and hence, it is reasonable to compare the average void volume predicted by the model with those obtained from the experimental data. Table 2 gives the average void volumes calculated from the model and the corresponding experimentally measured values. Observe that the model underestimates the average void volume for all specimens, by a factor of 2 or more.

McClintock [2] has proposed a model for void growth, which predicts growth of an elliptical hole in a viscous material under an applied stress, using an axisymmetric geometry. However, McClintock's model is considered to be a good approximation for growth of spherical voids as well, and recently it has been successfully applied to model damage evolution involving nucleation, growth, and coalescence of voids in
Table 2

Comparison of experimental average void volume and average void volume predicted by Rice and Tracey model

\begin{tabular}{lcc}
\hline $\begin{array}{l}\text { Displacement } \\
(\%)\end{array}$ & $\begin{array}{l}\text { Experimental average } \\
\text { void volume }\left(\mu \mathrm{m}^{3}\right)\end{array}$ & $\begin{array}{l}\text { Theoretical (model) aver- } \\
\text { age void volume }\left(\mu \mathrm{m}^{3}\right)\end{array}$ \\
\hline $\begin{array}{l}\text { Notch } \\
97\end{array}(R=19.8 \mathrm{~mm})$ & $V_{0}(80 \%)=64.2 \mu \mathrm{m}^{3}$ \\
94 & 142.5 & 75 \\
89 & 174.8 & 73 \\
Notch 2 & 69 \\
94 & 125 & $6.49 \mathrm{~mm})$ \\
85 & 209 & $V_{0}(76 \%)=98 \mathrm{~m}^{3}$ \\
& 213 & 103 \\
\end{tabular}

three-dimensional microstructure of a cast A356 alloy [7,8]. McClintock's model (see Eq. (3)) reveals that stress triaxiality, strain-hardening coefficient, strain rates, temperature regimes, etc. have dominant influence on

\section{Notch 1}

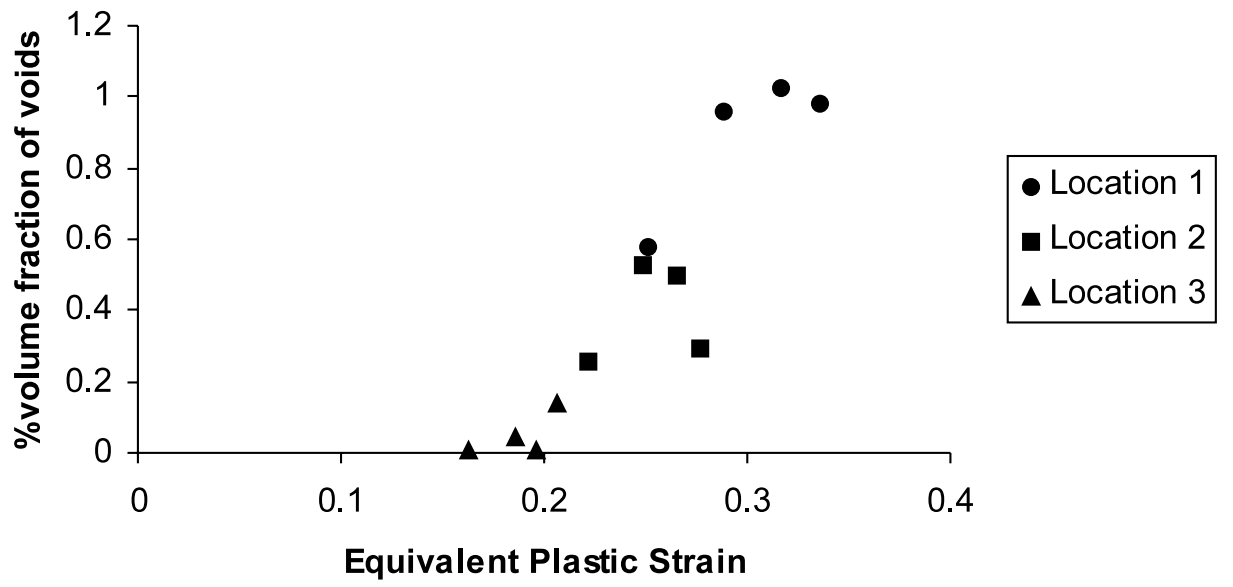

Fig. 9. Plot of void volume fraction (\%) versus equivalent plastic strain for specimens having $19.8 \mathrm{~mm}$ notch radius. 
Table 3

Comparison of experimental average void volume and average void volume predicted by McClintock model

\begin{tabular}{lcc}
\hline $\begin{array}{l}\text { Displacement } \\
(\%)\end{array}$ & $\begin{array}{l}\text { Experimental average } \\
\text { void volume }\left(\mu \mathrm{m}^{3}\right)\end{array}$ & $\begin{array}{l}\text { Theoretical (model) aver- } \\
\text { age void volume }\left(\mu \mathrm{m}^{3}\right)\end{array}$ \\
\hline $\begin{array}{l}\text { Notch } 1 \\
97\end{array}(R=19.8 \mathrm{~mm})$ & $V_{0}(80 \%)=64.2 \mu \mathrm{m}^{3}$ \\
94 & 142.5 & 208 \\
89 & 174.8 & 142 \\
Notch $2(R=2.49 \mathrm{~mm})$ & $V_{0}(76 \%)=98 \mu^{3}$ \\
94 & 209 & 109 \\
85 & 213 & 581 \\
\hline
\end{tabular}

the void growth rate. The average void volume was calculated by using Eq. (3) with the value of the strainhardening coefficient equal to 0.068 and the stresses and strains computed from FE-simulation. Table 3 gives the values of average void volume calculated from the McClintock's model and the corresponding experimentally measured values. Observe that there is a significant discrepancy between the predictions of McClintock's model and the experimental data on the void growth for the specimens having notch radius of $2.49 \mathrm{~mm}$. The main reason for lack of agreement between the void growth models proposed by Rice and Tracy, and McClintock, and the experimental data is the interactions between the neighboring voids, which has not been accounted for in the models. Further, in the present alloy, even at a given location in the specimen, all the voids do not nucleate (or get activated) at the same equivalent plastic strain, i.e. a continuous void nucleation takes place. Consequently, at a given point in the load/displacement path of the specimen, the size of given void also depends on the equivalent plastic strain at which it nucleated. The continuous void nucleation leads to a distribution of void sizes, as observed experimentally. The void growth equations that model the growth history of a single void are applicable to an ensemble of voids, only if all voids nucleate simultaneously, or if the continuous nucleation events are accounted for in the void growth and volume fraction calculations. The present void growth calculations do not account for such continuous nucleation of voids. This is another important reason for the lack of agreement between the experimental data and the calculated average void volumes. As all analytical void growth models ignore the interactions among the neighboring voids, and it is difficult to account for continuous void nucleation/activation, a good agreement between other analytical void growth models and the experimental data on average void volume is also not expected. Therefore, to predict failure locations in the extruded 6061 Al-alloy components (in T6 condition) of complex geometry under multi-axial loading conditions, it is of interest to develop an empirical damage evolution law from the experimental data.

\subsection{Empirical damage evolution equation}

The volume fraction of voids has been measured at different locations in the notch tension test specimens of two different notch radii, strained to different displacements. The local stresses and strains at these locations have been computed by using FE-simulations. These data can be used to develop an empirical relationship between the void volume fraction, and attributes of local stresses and strains. The void volume fraction is governed by the void nucleation and void growth rate, which are sensitive to stress triaxiality and equivalent plastic strain. Therefore, an empirical equation contain-

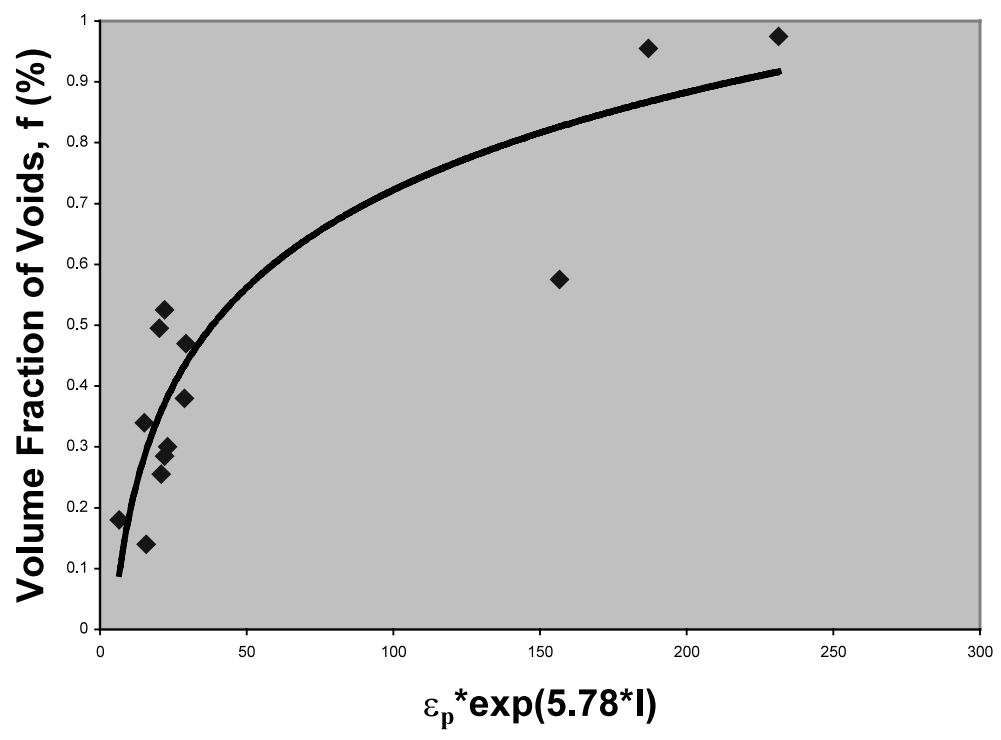

Fig. 10. Empirical damage evolution rule. 
ing these two parameters is proposed. Fig. 10 shows a plot of void volume fraction at a given location (Fig. 5) versus the quantity $\left[\varepsilon_{\mathrm{p}} \exp (5.78 I)\right]$ for the corresponding location, displacement, and notch-radius obtained from the FE-simulation. Observe that the volume fraction data for all three locations, four displacements, and two different notch radii fall on one trend curve. An empirical equation for the trend curve for the data trend in Fig. 10 is as follows:

$f=a+b \ln \left[\varepsilon_{\mathrm{p}}\right]+c I$

where $f$ is the void volume fraction expressed as $\%, \varepsilon_{\mathrm{p}}$ is the equivalent plastic strain, and $I$ is the stress triaxiality. In this empirical equation, $a, b$, and $c$ are material constants, whose values are $a=-0.3447, b=0.2317$ and $c=1.34$. Eq. (4) is an empirical relationship specific to the damage evolution in extruded 6061 Al-alloy in peak-aged (T6) condition. Note that the values of the constants $a, b$, and $c$ are expected to depend on the alloy chemistry, heat treatment, and the initial microstructure. This correlation covers the stress triaxiality values from 0.75 to 1.34 , equivalent plastic strain from 0.006 to 0.338 , and void volume fraction in the range of $0.14-1.11 \%$. Note that this empirical equation may be used for interpolation, but not for extrapolation. The relationship is useful for computation of the local microstructural damage (void volume fraction) at different locations in components of complex geometry subjected to multi-axial loading, where the local stress states can be calculated for given boundary conditions by using FE-simulations, provided that the stress triaxiality and equivalent plastic strains are in interpolation range. Such computations are useful for prediction of location(s) and load(s) at which the component is likely to fail $[7,8]$ for given boundary conditions.

\section{Summary and conclusions}

Void growth has been monitored in a peak-aged 6061 Al-alloy under triaxial stress state via estimation of volume fraction and number density of voids by using stereological and image analysis techniques. There is no agreement between the experimental data on the average void volume and the predictions of the analytical void growth models due to interactions between neighboring voids, which are ignored in the models. The experimental damage data and FE-simulations have been used to arrive at an empirical damage evolution relationship between the void volume fraction, local equivalent plastic strain, and stress triaxiality.

\section{Acknowledgements}

This research was supported through research grants from U.S. National Science Foundation (Grant no. DMR-9816618), and Sandia National Laboratories, Livermore, CA under DOE Contract no. DE-AC0495AL85000. The financial support is gratefully acknowledged.

\section{References}

[1] H. Agarwal, M.S. Thesis Dissertation, Georgia Institute of Technology, Atlanta, GA, 2001.

[2] F.A. McClintock, ASME J. Appl. Mech. 35 (1968) 363.

[3] A.L. Gurson, J. Eng. Mater. Technol. 99 (1977) 2.

[4] A.B. Richelsen, V. Tvergaard, Acta Metall. Mater. 42 (1994) 2561.

[5] V. Tvergaard, J. Mech. Phys. Solids 44 (1996) 1237.

[6] J.R. Rice, D.M. Tracey, J. Mech. Phys. Solids 17 (1969) 201.

[7] M.F. Horstmeyer, A.M. Gokhale, Int. J. Solids Struct. 36 (1999) 5029.

[8] M.F. Horstemeyer, J. Lathrop, A.M. Gokhale, M. Dighe, Theor. Appl. Fract. Mech. 33 (2000) 31.

[9] P. Louis, A.M. Gokhale, Metall. Trans. A 26A (1995) 1449.

[10] A. Tewari, A.M. Gokhale, J. Microsc. 200 (2000) 227.

[11] R.T. DeHoff, F.N. Rhines, Quantitative Microscopy, McGrawHill, New York, NY, 1968.

[12] E.E. Underwood, Quantitative Stereology, Addison-Wesley, Reading, MA, 1970. 